\title{
Breves reflexões sobre o Programa de Saúde da Família...
}

\author{
Brief reflections on the Family Healthcare Program...
}

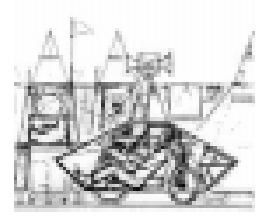

Alexandre Nemes Filho ${ }^{1}$

O texto trata de uma temática complexa ao abordar movimentos com graus de autonomia relativa, o da academia $e$ dos serviços, $e$ as possibilidades de sua articulação determinada por uma política específica posta em prática através do PSF.

Situa bem a trajetória do movimento da medicina de família e da reforma sanitária brasileira, mas é a este aspecto que se dirige nossa primeira crítica.

Ao abordar a especificidade da reforma sanitária brasileira, os autores fazem referência à falta de percepção em relação às questões "micro" nas propostas de modelo assistencial para o SUS.

No movimento da reforma sanitária, a discussão em torno do modelo assistencial tem se constituído em um eixo importante, aliada às questões políticas e jurídico-institucionais. A referência única aos SILOS e aos Distritos de Saúde inseridos na legislação salienta apenas o caráter estratégico da descentralização no SUS e não traduz, como sabemos, a realidade da produção teórica, nem as experiências acumuladas pela saúde coletiva em diferentes aspectos da organização dos serviços.

A prática assistencial adotada por vários serviços e municípios tem se orientado a partir de referências teóricas presentes, por exemplo, nas propostas das Ações Programáticas, da Vigilância à Saúde e da Clínica Ampliada. Estas construções teórico-operacionais buscam direcionar as ações de saúde no sentido da integralidade, da humanização, da aproximação usuário-serviço e voltam-se particularmente para o nível local.

O PSF não surge como uma proposta alternativa de modelo assistencial,

\footnotetext{
${ }^{1}$ Médico sanitarista do Centro de Saúde Samuel B. Pessoa, Faculdade de Medicina da Universidade de São Paulo; Diretor do Distrito de Saúde Escola do Butantã, Secretaria Municipal de Saúde de São Paulo.<alenemes@usp.br>
} 
mas é inegável que, com a dimensão na qual sua implantação vem ocorrendo, verifica-se um impacto na organização da atenção básica talvez não alcançado em outro momento. Cria então condições para iniciativas de reorientação do modelo assistencial a partir do âmbito municipal, ainda que em alguns municípios mantenha-se a implantação pró-forma, mencionada pelos autores.

No município de São Paulo, face a sua característica peculiar de estar reingressando no SUS com o fim do Plano de Atendimento à Saúde (PAS), a proposta do PSF tem causado muita inquietação, adesões e resistências.

Há uma forte cultura favorável à assistência calcada no modelo ambulatorial tradicional e críticas quanto à presença do generalista em centros com oferta muito grande de todas as especialidades médicas. Mas a questão de maior entrave para a administração é realmente a carência de profissionais para a implantação do PSF.

Até hoje, a principal estratégia adotada para a formação de recursos humanos no SUS esteve baseada na formação de sanitaristas, quer para intervenção nas ações específicas da "saúde pública, como as vigilâncias, quer para oferecer competências para o exercício da gerência dos serviços e agora em particular para a gestão municipal. Esta formação é dada através de variados cursos de especialização ou nas residências de medicina preventiva/social".

No PSF presenciamos uma mudança radical no tocante à equipe que presta atendimento, em particular pela presença do médico generalista, do vínculo com a clientela e da proposição de trabalho em equipe. Demanda então, para sua continuidade, novas tarefas do aparelho formador.

Os autores chamam atenção para a conjuntura atual, favorável a uma mudança na formação acadêmica, voltada para o novo chamamento do setor. Nesse sentido, a instituição da parceria através dos Pólos de Capacitação vem cumprindo o papel de habilitar os profissionais da equipe para a abordagem da atenção integral prevista no PSF. Mas, conforme relato das equipes, existem problemas em manter as atividades de educação continuada no ritmo programado.

Ressente-se, no texto, de uma discussão quanto à abordagem para alcançar estas transformações no núcleo das práticas educacionais, nos níveis da graduação e pós-graduação.

Como atuar na direção da intersetorialidade? De que formação

${ }^{2}$ O Distrito de Saúde Escola do Butantã constitui-se através de uma parceria entre a Secretaria Municipal de Saúde de SP e a

Faculdade de Medicina Escola de Enfermagem e Faculdade de Saúde Pública, da

Universidade de São Paulo, para atuação conjunta na gestão, ensino e pesquisa, no âmbito da região do Butantã, contando com seus serviços de saúde. necessitamos para que estes profissionais, em especial os médicos, atendam a este novo perfil? A criação de residências multiprofissionais é a saída para atender à questão apontada?

Em São Paulo, as mudanças na administração municipal reiniciaram uma aproximação entre as escolas e a Secretaria Municipal de Saúde .Nas discussões do Distrito de Saúde Escola do Butantã ${ }^{2}$, tem surgido diferentes visões em relação às mudanças na formação do médico e dos demais profissionais da saúde. A maior parte delas demonstra a intenção de promover o deslocamento dos alunos da graduação do hospital para a rede de serviços básicos de saúde, aproximando-os dos problemas do usuário e da comunidade e do conhecimento do trabalho da equipe do PSF nas intervenções sobre o coletivo.Temos também setores mais preocupados com 
a resolução de questões internas ao hospital escola e que vêem estas soluções relacionadas com a implantação de uma rede mais resolutiva na primeira linha.

Estas considerações evidenciam as peculiaridades deste processo específico, mas estamos de acordo que um bom caminho pode ser a parceria entre as instituições formadoras e os serviços, visando as mudanças éticas $e$ sociais apontadas no texto.

Recebido para publicação em: 08/06/01. Aprovado para publicação em: 16/07/01.

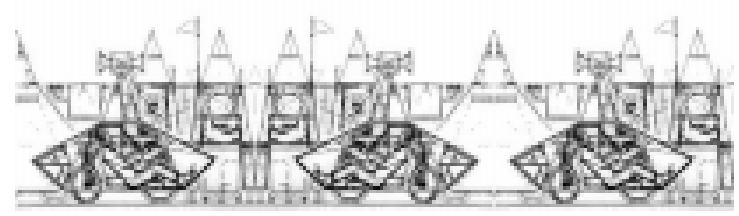

